\title{
Tuberculous Mastitis: Experience of Five Cases at a Tertiary Care Hospital
}

\author{
Md. Hasanuzzaman ${ }^{1}$, Md. Johirul Islam², A Z M Mostaque Hossain³, \\ Mohammad Zillur Rahman ${ }^{4}$, Md. Ashraf-U1 Haque ${ }^{5}$, Md. Mamun Or Rasheed ${ }^{6}$
}

\begin{abstract}
Background: Tuberculous Mastitis (TM) is a rare form of tuberculosis, even in countries where the burden of tuberculosis is high. It may mimic other systemic illness, even carcinoma breast, a condition with which it may coexist. Objective: To disseminate the message to the concerned expertise that it can present a diagnostic problem on radiological and microbiological investigations, and thus a high index of suspicion is needed. Materials and method: This observational study was carried out in the department of Surgical Oncology of National Institute of Cancer Research \& Hospital (NICRH), Dhaka, Bangladesh from January 2010 to December 2015. During the study period only five cases of TM were identified and all were included in the analysis purposively. Results: Mean $( \pm S D)$ age of the patients was 27.2( \pm 16.22$)$ years. AFB in pus was found in one patient. Fine Needle Aspiration Cytology (FNAC) was done in four AFB negative patients and granulomatous lesions were found in each case. Histopathological examinations of two resected breast lumps also showed granulomatous lesions consistent with tuberculosis. Breast ultrasound showed multilocular abscess with ill-defined lump in two cases, solitary lump in two patients and cystic lesion in one patient. Axillary lymphadenopathy was found in one patient with solitary lump. Repeated image guided aspiration of the abscess was performed in 3 cases. Two patients underwent lumpectomy operation. All five patients were given anti-TB chemotherapy for 6 months. All of them recovered fully after completion of Category I treatment. Conclusion: Though it is a great mimicker with proper evaluation the disease is curable with antitubercular drugs, and in some cases surgery is required. Keywords: Mastitis; breast tuberculosis; granulomatous lesions; antitubercular drugs.
\end{abstract}

Delta Med Col J. Jul 2016;4(2):67 - 70

\section{Introduction}

Tuberculosis is the most prevalent human involve any organ and mimic other illness. infection throughout the globe. The infection can Tuberculosis of the breast is an uncommon

1. Registrar, Department of Surgical Oncology, National Institute of Cancer Research \& Hospital (NICRH), Dhaka, Bangladesh.

2. Assistant Professor, Department of Cancer Epidemiology, NICRH, Dhaka, Bangladesh.

3. Professor \& Head, Department of Surgery, Dhaka Medical College, Dhaka, Bangladesh.

4. Junior Consultant, Department of Surgical Oncology, NICRH, Dhaka, Bangladesh.

5. Associate Professor, Department of Surgery, Kushtia Medical College, Kushtia, Bangladesh.

6. Medical Officer, Department of Oncology, Bangabandhu Sheikh Mujib Medical University, Dhaka, Bangladesh.

Correspondence: Dr. Md. Hasanuzzaman. e-mail: hasanuzzaman1959@gmail.com 
presentation of tuberculosis, even in countries where the burden of tuberculosis is high. ${ }^{1,2}$ Tuberculous mastitis (TM) is a rare extrapulmonary presentation of tuberculosis which accounts for less than $1 \%$ of all diseases of the breast in the developed countries. ${ }^{1-5}$ Incidence of this disease is higher in countries endemic for tuberculosis, like the Indian subcontinent, where it may be as high as $4 \% .^{2}$

Sir Astley Cooper reported the first case of TM in 1829.6 Tuberculous mastitis may be part of a systemic disease or may be the only manifestation of tuberculosis. It occurs far more frequently in women, especially in their reproductive age, and is uncommon in prepubescent and elderly women. ${ }^{7,8}$ This could be because the female breast undergoes frequent changes during the period of childbearing activity and is more susceptible to trauma and infection. ${ }^{9}$

The risk factors associated with TM include multiparity, lactation, trauma, past history of suppurative mastitis, and AIDS. ${ }^{10,11}$ It may be difficult to differentiate from carcinoma breast, a condition with which it may coexist. ${ }^{12,13}$

\section{Materials and method}

This observational study was carried out in the department of Surgical Oncology of National Institute of Cancer Research \& Hospital (NICRH), Dhaka, Bangladesh from January 2010 to December 2015. The study was approved by the Ethical Review Committee of NICRH and informed consent was taken from each patient before their enrollment in the study. During the study period only five cases of TM were identified and all were included in the study. Sampling was convenient and purposive. Results were expressed as proportions and mean $( \pm \mathrm{SD})$.

\section{Results}

Five female patients of TM were included in the study. Mean $( \pm \mathrm{SD})$ age of the patients was 27.2
$( \pm 16.22)$ years and the age ranges from 14 years to 55 years. All of them were from average socio-economic status. Three out of 5 patients were married (Table I).

Table I: Socio-demographic characteristics of the patients

\begin{tabular}{ll}
\hline Variables & Values \\
\hline Age in years & \\
Mean \pm SD & $27.2 \pm 16.22$ \\
Range & $14-55$ \\
Married (n, \%) & $3(60)$ \\
Average SES (n, \%) & $5(100)$ \\
\hline
\end{tabular}

$\mathrm{SES}=$ Socio-economic status

All the patients had raised ESR and increased lymphocyte counts. X-ray chest $\mathrm{P} / \mathrm{A}$ view of all five patients revealed no abnormality. AFB in pus was found in one patient. Fine Needle Aspiration (FNA) was done in four AFB negative patients and granulomatous lesions were found in each case. Histopathological examinations of two resected breast lumps also showed granulomatous lesions consistent with tuberculosis (Table II).

Table II: Diagnostic characteristics of the patients

\begin{tabular}{ll}
\hline Variables & Values \\
\hline Raised ESR (n, \%) & $5(100)$ \\
Raised lymphocyte count (n, \%) & $5(100)$ \\
Positive pus for AFB (n, \%) & $1(20)$ \\
Granulomatous lesion on FNAC (n, \%) & $4(100)$ \\
Granulomatous lesion on HP (n, \%) & $2(100)$ \\
\hline
\end{tabular}

$\mathrm{FNAC}=$ Fine needle aspiration cytology $\mathrm{HP}=$ Histopathology

Breast ultrasound showed multilocular abscess with ill-defined lump in two cases, solitary lump in two patients and cystic lesion in one patient. Axillary lymphadenopathy was found in one patient with solitary lump (Table III).

\section{Table III: USG findings of the patients}

\begin{tabular}{ll}
\hline Variables & Values \\
\hline Multi-locular abscess with ill-defined & \\
lump $(\mathrm{n}, \%)$ & $2(40)$ \\
Solitary lump (n, \%) & $2(40)$ \\
Cystic lesion (n, \%) & $1(20)$ \\
\hline USG= Ultrasonography
\end{tabular}


Repeated (once in each month) image guided aspiration of the abscess was performed in 3 cases. Two patients underwent lumpectomy operation. But all five patients were given anti-TB chemotherapy for 6 months $(2$ months of Isoniazid, Rifampicin, Pyrazinamide, and Ethambutol and months of Isoniazid and Rifampicin). All five patients recovered fully after completion of Category I treatment (Table IV).

Table IV: Clinical characteristics of the patients

\begin{tabular}{ll}
\hline Variables & Values \\
\hline Treatment & \\
$\quad$ Repeated image guided aspiration of the & \\
abscess with anti TB (n, \%) & $3(60)$ \\
$\quad$ Lumpectomy with anti TB (n, \%) & $2(40)$ \\
\hline
\end{tabular}

SES $=$ Socio-economic status

\section{Discussion}

In tuberculous mastitis a solitary, ill-defined, hard lump is often found in the central or upper outer quadrant of a breast.7,14,15 Multiple lumps and bilateral involvement are uncommon and occur in less than $3 \%$ of the patients. ${ }^{14,16}$ In a series of 30 patients reported by Tewari \& Shukla ${ }^{17}, 22$ patients presented with lump in the breast; 11 of these had tubercular ulcer, and 4 had multiple discharging sinuses in the overlying breast skin. In the present study multilocular abscess with ill-defined lump were in two cases, solitary lump in two patients and cystic lesion in one patient on breast ultrasound was found.

The gold standard diagnosis of TM is by bacteriological culture of breast tissue or by Ziehl Neelsen (ZN) stain. ${ }^{10}$ However, in TM the bacilli are isolated in only $25 \%$ of cases, and acid-fast bacilli (AFB) are identified only in $12 \%$ of the patients. Therefore, demonstration of caseating granulomas from the breast tissue and involved lymph nodes may be sufficient for the diagnosis. $5,17,18$ In our study, in one patient out of five (20\%) AFB was identified in pus. Fine needle aspiration cytology (FNAC) is the most widely used initial invasive method for diagnosis of breast tuberculosis. Approximately $73 \%$ of the cases of TM can be diagnosed on FNAC when both epithelioid cell granulomas and necrosis are present. ${ }^{5,19}$ In the present study FNAC was done in four cases and granulomatous lesions were found in all instances. In tuberculosis-endemic countries, the finding of granuloma in fine needle aspiration warrants empirical treatment for tuberculosis even in the absence of positive acid fast bacilli (AFB) and without culture results. 5,20 We performed repeated image guided aspiration of the abscess in 3 cases. Lumpectomy was done on two patients as FNAC was not conclusive. Most importantly all five patients were given Category I anti-TB chemotherapy for 6 months and all of them recovered fully after completion of the treatment.

Tuberculosis of the breast is called the great mimicker. It can present a diagnostic problem on radiological and microbiological investigations, and thus a high index of suspicion is needed. Incorporating a highly sensitive technique like PCR may be helpful in confirming the diagnosis early. However in our cases no GeneXpert test or PCR based DNA study was done for confirmation of TB. The disease is curable with anti-tubercular drugs, and in some casessurgery is required.

\section{References}

1. Harris SH, Khan MA, Khan R, Haque F, Syed A, Ansari MM. Mammary Tuberculosis: Analysis of Thirty-Eight Patients. ANZ J Surg. 2006;76:234-37.

2. Tse GM, Poon CS, Ramachandram K, Ma TK, Pang LM, Law BK, et al. Granulomatous Mastitis: A Clinicopathological Review of 26 Cases. Pathology. 2004;36:254-57.

3. Morgan M. Tuberculosis of the Breast. Surg Gynecol Obstet. 1931;53:593-605.

4. Kalac N, Ozkan B, Bayiz H, Dursun AB, Demirag F. Breast Tuberculosis. Breast. 2002;11:346-49. 
5. Kakkar S, Kapila K, Singh MK, Verma K. Tuberculosis of the Breast: A Cytomorphologic Study. Acta Cytol. 2000;44(3):292-96.

6. Cooper A. Illustration of the Diseases of the Breast. Part I. London: Longman, Rees, Orme, Brown and Green; 1829. p.7.

7. Jalali U, Rasul S, Khan A, Baig N, Khan A, Akhter R. Tuberculous Mastitis. J Coll Physicians Surg Pak. 2005;15:234-37.

8. O'Reilly M, Patel KR, Cummins R. Tuberculosis of the Breast Presenting as Carcinoma. Mil Med. 2000; 165:800-802.

9. Raw N. Tuberculosis of the Breast. Br Med J. 1924;1(3302):657-58.

10. Gupta PP, Gupta KB, Yadav RK, Agarwal D. Tuberculous Mastitis: A Review of Seven Consecutive Cases. Indian J Tub. 2003;50:47-50.

11. Gilbert AI, McGough EC, Farrell JJ. Tuberculosis of the Breast. Am J Surg. 1962;103:424-27.

12. Fujii T, Kimura M, Yanagita Y, Koida T, Kuwano H. Tuberculosis of Axillary Lymph Nodes with Primary Breast Cancer. Breast Cancer. 2003;10:175-78.

13. Graunsman RI, Goldman ML. Tuberculosis of the Breast-Report of Nine Cases Including Two Cases of Co-Existing Carcinoma and Tuberculosis. Am J Surg. 1945;67:48.
14. Banerjee A, Green B, Burke M. Tuberculous and Granulomatous Mastitis. Practitioner. 1989;233:754-56.

15. Shinde SR, Chandawarkar RY, Deshmukh SP. Tuberculosis of the Breast Masquerading as Carcinoma: A Study of 100 Patients. World J Surg. 1995;19:379-81.

16. Elmrabet F, Ferhati D, Amenssag L, Kharbach A, Chaoui A. Breast Tuberculosis. Med Trop (Mars). 2002;62:77-80.

17. Tewari M, Shukla HS. Breast Tuberculosis: Diagnosis, Clinical Features and Management. Indian J Med Res. 2005;122:103-10.

18. Gupta D, Rajwanshi A, Gupta SK, Nijhawan R, Saran RK, Singh R. Fine Needle Aspiration Cytology in the Diagnosis of Tuberculous Mastitis. Acta Cytol.1999;43:191-94.

19. Martinez-Parra D, Nevado-Santos M, Melendez-Guerrero B, García-Solano J, Hierro-Guilmain CC, Pérez-Guillermo M. Utility of Fine Needle Aspiration in the Diagnosis of Granulomatous Lesions of the Breast. Diagn Cytopathol. 1997;17:108-14.

20. Mehrotra R. Fine Needle Aspiration Diagnosis of Tuberculous Mastitis. Indian J Pathol Microbiol. 2004;47:377-80. 